\title{
Una merced de los Reyes Católicos al duque de Alba relacionada con la expulsión de los judíos
}

\author{
M. Dolores-Carmen Morales Muñiz *
}

El 20 de marzo de 1492 se decide la expulsión de la comunidad hebrea de España consecuencia, al parecer inevitable, de la madurez política representada por el estado moderno recién nacido así como del establecimiento de la Inquisición. El decreto de expulsión permitía a los judíos que habían decidido no abandonar su fe la conservación de sus bienes. No obstante dicho decreto contemplaba, en este particular, algunas cuestiones como la prohibición de sacar, entre otros bienes, oro y plata ${ }^{1}$.

El problema resultaba harto complejo al convertirse los judíos en acreedores y deudores con todas las consecuencias que esto conllevaba ya que, en ocasiones, las cantidades adeudadas por los judíos procedían de rentas públicas «de las que eran arrendatarios pero que ya no les sería posible percibir ${ }^{2}$. El problema de las deudas, pues, se convertía en un problema de cierta importancia teniendo más difícil solución aquellas de que eran acreedores los cristianos por lo que los reyes hubieron de nombrar jueces comisarios ${ }^{3}$.

* Profesora-tutora del Centro Asociado de Madrid. UNED.

- Sobre la expulsión de la comunidad judía se han escrito, lógicamente muchos trabajos. L. SuÁREZ FERNÁNDEZ en su libro Judíos españoles en la Edad Media, 1980, ha analizado la promulgación del decreto, pág. 268 y siguientes, y recoge, también, en las págs. 285-286 abundante bibliografía.

2 Del mismo autor Documentos acerca de la expulsión de los judíos, 1964, pág. 51.

3 Ibidem, «en contratos directos entre judíos y cristianos... el arreglo era más difícil... se permitía a otras personas traspasar el cobro de sus deudas mediante una venta de éstas - lo que implicaba pérdidas - o simplemente apoderamiento a otras personas». 
También, y a fin de que los judíos pudieran conservar sus bienes éstos tuvieron que transformarse - se entiende que lo anteriormente expuesto como prohibido- en letras de cambio. Letras de cambio que les serían hechas efectivas en plazas comerciales fuera de las fronteras. La necesidad de vender tuvo consecuencias que no se hicieron esperar y muchos especuladores -conversos generalmente- se enriquecieron al hacerse cargo de las deudas y bienes de los judíos. Se sabe que parte del dinero obtenido con la venta de aquellas ventas y deudas de los judios fue a parar a manos de mercaderes genoveses quienes lo convirtieron en letras de cambio ${ }^{4}$.

Otros bienes transformados en oro y plata se enfrentaban directamente con la normativa del decreto de expulsión que impedía la salida de los metales preciosos fuera de las fronteras del país. Ha de comprenderse que nos hallamos ante una mentalidad típicamente mercantilista que consideraba a los metales preciosos como la clave de la prosperidad de un país y que, por lo tanto, la riqueza consistía en su atesoramiento. Aquella prohibición no fue respetada y muchos desterrados, especialmente a través de la frontera de Portugal sacaron grandes cantidades de oro y plata y moneda acuñada, ayudados por cristianos y burlando la vigilancia.

Desde el 6 de octubre de 1492 se habian comenzado a impartir órdenes para que se realizaran los informes sobre las deudas dejadas por los judios. La cuestión ofrecía sus dificultades y los jueces comisarios tuvieron que resolver tanto la cuestión de aquellos judios cuyas deudas sobrepasaban a los bienes visibles como la queja de los cristianos víctimas de la usura $^{5}$. Los informes minuciosos que los Reyes Católicos - tras la salida de los judíos-ordenaron realizar en todas las fronteras se fue retrasando y los monarcas hubieron de aplicar el sistema de marca. Esto enlaza con el tema principal de este artículo: Isabel y Fernando al no disponer de medios suficientes para perseguir a los culpables decidieron confiscar para sí todos los bienes, deudas o letras de cambio - algunas desde Italia o Inglaterra- que los judíos poseían aún en España ${ }^{6}$.

4 lbidem, pág. 52.

5 Ibidem. Muchas deudas de judíos eran procedentes de contratos usuarios y rechazadas, no pagables.

- Toda la fortuna de los judíos - fruto de la conversión de oro, plata, monedas, armas y caballos - transformada en letras de cambio fue ganancia para los banqueros internacionales. Los Reyes Católicos no obstante, castigaron también a los funcionarios prevaricadores - caso de Diego de Vera alcalde mayor de sacas de Badajoz- que como guardas de 
Un largo trabajo de información que duraría hasta 1494 provocó que, por decreto, deudas, bienes y letras de cambio revertían en beneficio del tesoro público. El 26 de julio de aquel año, los monarcas dispusieron que se cobrasen todas las deudas pendientes, pasando su importe a la Cámara ${ }^{\text {. }}$.

Este largo preámbulo enlaza con los dos documentos que en este muy corto trabajo presentamos. Son dos cédulas de merced a favor del segundo duque de Alba, Fadrique Álvarez de Toledo. Por la una el rey Fernando le concedió a este personaje los bienes y deudas que los judíos expulsados de tierras del duque quedaron debiendo. Por el segundo documento -cronológicamente anterior- los Reyes Católicos hacian merced a don Fadrique Álvarez de Toledo de los bienes y deudas que los judíos expulsados de los obispados de Salamanca, Ávila, Coria y Ciudad Rodrigo, en atención a la pérdida que en vasallos y rentas había tenido el duque ${ }^{8}$.

No es la primera vez que los monarcas actuaban así en relación con los bienes de esta comunidad y su donación a un miembro de la alta nobleza. El mismo año de la expulsión los reyes hicieron merced al duque del Infantado, Iñigo López de Mendoza, de «todos los bienes, muebles, rraices y movimientos que todos los judios que bivian en sus tierras y lugares" ${ }^{9}$.

Examinemos ahora brevemente, volviendo a nuestro tema inicial, al duque de Alba. ¿En qué medida le beneficiaba a él directamente aquella merced? La confiscación de las deudas y bienes de los judíos hacía un indudable perjuicio en muchas comarcas al tratarse de créditos comerciales, por ello los nobles llegaban a protestar y, en algún caso, se les anulaba aquellas deudas. En el caso de los bienes parece claro que pasaban automáticamente a engrosar los bienes comunales del señorío. Al anular las deudas, los reyes en realidad más que hacerles un favor directo -no era exactamente para los nobles- aquél revertía en beneficio de sus señorios que se habian visto desagradablemente afectados por las deudas tanto como por la incautación de los bienes de los judíos.

la frontera habian permitido a los judíos las saca de lo prohibido. El mismo autor en Los Trastámara y la Unidad Española, 1369-1517, 1981, págs. 6, 563-564.

7 L. SUÁREZ: Documentación..., pág. 62.

8 En Apéndices I y II.

9 F. CANTERA BURGos: "La judería de San Martín de Valdeiglesias", hace un exhaustivo examen del inventario de bienes de la comunidad hebrea, Sefarad, 1969, pág. 226. 
De esta manera puede concluirse que es una merced de interés para las tierras del duque en los obispados de Salamanca, Ávila, Coria y Ciudad Rodrigo y esos vasallos se verían afectados para bien. El documento del 22 de noviembre de 1494 deja muy claro que sólo implicaba a las personas que habitaban en esos lugares y nunca fuera «... persona de fuera delas dichas villas... esto tal cobradlo..." Es decir, se otorga poder al duque para que se comportara como si de los mismos monarcas se tratara puesto que anteriormente ellos eran los dueños de aquellas deudas y bienes como anteriormente se ha expuesto.

Sin embargo y a pesar de tratarse de una merced para los vasallos del duque - «que non pidan nin demanden debda alguna e ningun vasallo vuestro" - la merced de Fadrique Álvarez de Toledo era quizás, una manera de pagar una deuda que los Reyes Católicos tenían con el prócer: la inversión que el duque había hecho en la recién terminada guerra de Granada es un hecho conocido. Sabemos que los nobles prestaron a los monarcas en aquella contienda más de doce millones de maravedís con el compromiso de devolución. Fadrique Álvarez de Toledo, que tan importante papel iba a desempeñar en Italia y en Navarra tiempo después, había sido nombrado ya en 1486, al abandonar los reyes la frontera granadina, capitán general de aquélla. Su figura - siempre fiel al rey católico- merece un estudio aparte sobre el que habría que plantearse el comenzarlo. Insistiendo, no obstante sobre lo recién comentado, Ladero Quesada sostiene que entre 1482-91 se llevaron a cabo "con desigual intensidad" préstamos de los nobles a los monarcas y las devoluciones fueron en principio más complicadas de lo previsto ${ }^{10}$. Fadrique Álvarez de Toledo no fue ajeno a este proceso y valga como muestra los documentos que aquí se presentan en este homenaje al profesor Eloy Benito Ruano.

10 M. A. Ladero Quesada: La Haciénda Real de Castilla en el siglo XV, 1973, págs. 221-222, la nobleza contribuyó con empréstitos importantes como se comprueba en los cuadros 319 y siguientes. No obstante, entre los próceres no aparece el duque de Alba, en esta fuente manejada por el profesor LADERO. 


\section{APÉNDICE DOCUMENTAL}

\section{APÉNDICE I}

1494, noviembre 22. Madrid

Cédula de los Reyes Católicos haciendo merced a don Fadrique Alvarez de Toledo de los bienes y deudas que los judios expulsados de los obispados de Salamanca, Ávila, Coria y Ciudad Rodrigo en atención a la pérdida que en vasallos y rentas habia tenido el duque.

ADA. Alba, Caja 156, núm. 46

EL REY E LA REYNA. Qualesquier nuestros pesquisydores, executores e reçebtores delos bienes delos judios delos obispados de Salamanca e Avila e Coria e Çibdad Rodrigo; sabed que nos, acatando la pérdida delos vasallos e dela renta que perdió el duque de Alba enlas sus villas e lugares delos dichos obispados solariegas, el dicho duque a cabsa dela yda delos dichos judios queremos faser al dicho duque delos bienes e debdas que dexaron enlas dichas sus villas e lugares delos dichos obispados los judios sus vasallos que dellas se fueron que nos pertenesçian. Por ende nos vos mandamos que enlo que toca alos bienes e debdas que los judios que bivian e moravan enlas dichas villas e lugares del dicho duque de alva encudays (?) en cosa alguna dello pero sy los tales judios devian algunos maravedís e otras cosas a personas de fuera delas dichas villas o avyan algunos bienes o debdos de fuera dellas, esto tal cobradlo para nos segund el thenor delos poderes nues- 
tros que para ello teneys. E non fagades ende al. Fecha en Madrid a XXVI dias de noviembre de noventa e quatro años.

Va escrito entre renglones o dis debdas. YO EL REY. YO LA REYNA.

Por mandado del rey e dela reyna Fernand Alvares. 


\section{APÉNDICE ॥}

1497, septiembre, 17. Ávila

Cédula del rey Fernando el Católico haciendo merced al duque de Alba don Fadrique Álvarez de Toledo, de todo lo que quedaron debiendo sus súbditos a los judios expulsados del reino.

ADA. Alba, Caja 156, núm. 47.

EL REY. Por faser bien e merçed a vos don Fadrique de Toledo duque de Alba, por la presente vos fago merçed de todas las debdas que qualesquier vuestro vasallos quedaron devyendo a qualesquier judio al tiempo qque se fueron de mis reynos de qualquier calidad que sean. E por esta mi carta mando a Alonso de Morales mi thesorero delo extraordinario e a otros qualesquier mis jueses e receptores delos bienos delos judios que non pidan nin demanden debda alguna a ningund vasallo vuestro de las que ellos quedaron devyendo alos dichos judios de qualquier qualidad quesea por quanto yo vos fago merçed dellas segund dicho es. Fecha en la çibdad de Avila a XVII dias de setiembre de noventa e syete años.

Por mandado del rey Johan de Coloma.

E en la villa de Bonilla çinco dias del mes de otubre de mill e qutroçientos e noventa e siete años en presencia de mi Juan Martines de Meseguer escribano publico del rey e dela reyna nuestros señores e su notario publico en la su corte de chancilleria e ante los testigos yuso escriptos ante el señor Lope de Vera contyno de sus altesas e jues esecutor delos bienes e fasiendas quelos judios dexaròn en esta provyn- 
çia de Avila, paresçio presente Alfonso de Vargas recabdador del muy magnifico duque de Alva e presentó ante el dicho señor Lope de Vera esta çedula del rey nuestro señor desta otra parte escripta el qual dicho señor Lope de Vera la tomó en sus manos y besola y la puso sobre su cabeça e dixo al quanto al cumplimento della quela obedesçia e obedesçiò y que está presto dela cumplir en todo e por todo segund que su altesa por ella manda. Testigos que fueron presentes Juan de Bonilla notario e Diego Sosa escribano, veçinos de Bonilla. E porque yo el dicho Juan escribano susodicho fuí presente alo que dicho es en uno con los dichos testigos firmé aqui mi nombre e lo daré por escribano signado si fuere neçesario tornandome esta fé. 